\title{
CONSEQUÊNCIAS DA PANDEMIA DE COVID-19 PARA A AVIAÇÃO CIVIL NO
}

BRASIL

\section{CONSEQUENCES OF THE COVID-19 PANDEMIC FOR CIVIL AVIATION IN \\ BRAZIL}

Versão do autor aceita publicada online: 31 maio 2021

Publicado online: 25 jun. 2021

Como citar esse artigo - American Psychological Association (APA): Senna, V., \& Souza, A. M. (2021). Consequências da pandemia de covid-19 para a aviação civil no Brasil. Exacta. DOI: https://doi.org/10.5585/exactaep.2021.19744.

\section{Viviane de Senna}

vivianedsenna@hotmail.com

https://orcid.org/0000-0003-2924-5813

Universidade Federal de Santa Maria - UFSM

Graduada em Administração pela UFN, Especialista em Gestão de Negócios pela UFN, Especilista em Estatística e Modelagem Quantitativa pela UFSM, Graduada pelo Programa Especial de Graduação de Formação de Professores Para A Educação Profissional pela UFSM, Mestra em Engenharia da Produção pela UFSM, doutoranda em Engenharia da Produção pela UFSM.

\section{Adriano Mendonça Souza}

amsouza.sm@gmail.com

https://orcid.org/0000-0002-1562-2246

Universidade Federal de Santa Maria - UFSM

Graduado em matemática pela FIC - Faculdade Imaculada Conceição - Santa Maria- RS-Brazil), Especialista em Estatística e Modelagem Quantitativa pela UFSM, Mestre em Engenharia da Produção pela UFSM, doutor em Engenharia da Produção pela UFSC e neste período atuou como pesquisador na Texas A \& M University (TX - USA), realizou post-doc no Instituto Superior da Ciência do Trabalho e da Empresa - ISCTE - Business School - Lisbon Institute - Portugal. Atualmente é Professor Titular do Departamento de Estatística (UFSM) atuando nos curso de Especialização em Estatística e Modelagem Quantitativa (UFSM) e no Mestrado em Engenharia de Produção (UFSM) assim como nos demais cursos de graduação da instituição. A partir de 2007 passou a avaliador de curso e avaliador institucional do MEC, além de ser referri de várias revistas científicas. Faz parte do corpo editorial da Revista Ciência e Natura e membro do comitê editorial da Editora-UFSM.

\section{Resumo}

As Companhias aéreas no Brasil têm grande desafio administrativo para se manterem de forma competitiva no mercado. No ano de 2020 a pandemia causada pelo vírus SARS-COV-2 impactou o setor e gerou uma crise econômica que se acentuou diante da medida sanitária de distanciamento social. O objetivo do estudo é realizar previsões para o ano de 2020 das séries de passageiros e carga paga e correio transportadas pela aviação civil brasileira utilizando a metodologia Box e Jenkins, efetuando-se comparações com os valores previstos e realizados para determinar o impacto no período de pandemia e o verificar o comportamento das séries. Os modelos ajustados para passageiros transportados foi um $\operatorname{SARIMA}(1,0,0)(2,1,0)_{12}$ para a 
carga paga e correio foi um e SARIMA $(0,1,1)(0,1,1)_{12}$, as perdas estimadas para o ano de 2020 foram de, no mínimo, 27,82\% e 21,30\% respectivamente, para passageiros e carga paga e correio transportados, podendo chegar próximo dos 55\%. Os resultados indicam grandes desafios para a manutenção das Companhias no mercado doméstico devido a grandes perdas de receita envolvidas.

Palavra-Chave: Aviação civil. ARIMA. Séries temporais. Pandemia. SARS-COV-2.

\begin{abstract}
Airlines in Brazil have a great administrative challenge to remain competitive in the market. In the year 2020, a pandemic caused by the SARS-COV-2 virus impacted the sector and generated an economic crisis that was accentuated by the health measure of social distance. The objective of the study is to carry out for the year 2020 the series of passengers and paid cargo and mail transported by Brazilian civil aviation using the methodology and Jenkins, making comparisons with the results, and carried out to determine the impact on the pandemic period and o check the behavior of the series. The adjusted models for passengers transported to a SARIMA(1.0.0)(2.1.0) $)_{12}$ for cargo paid and mail was one and SARIMA(0.1.1)(0.1.1) ${ }_{12}$, the estimated losses for the year 2020 were, at least, $27.82 \%$ and $21.30 \%$ respectively, for passengers and paid cargo and mail transported, which may reach close to 55\%. The results resulted in great challenges for the maintenance of the Companies in the domestic market due to the large losses of revenue involved.
\end{abstract}

Keywords: Civil Aviation. ARIMA. Time series. Pandemic. SARS-COV-2.

\title{
Introdução
}

As modificações de cenário econômico mundial impostas pela pandemia de SARSCOV-2 causaram a maior crise que o setor aéreo internacional já enfrentou (Rodrigues, 2020). $\mathrm{Na}$ aviação civil brasileira a expectativa de operação para o ano de 2020 foi bem díspar do realizado. A pandemia forçou o fechamento de aeroportos, redução do tráfego aéreo em aproximadamente $90 \%$ durante o mês de abril de 2020, pela chamada "malha aérea essencial", com o intuito de controlar o vírus (ANAC, 2020). Em um país com as dimensões continentais, como o Brasil, o transporte aéreo tem a capacidade de agilizar deslocamentos e conectar regiões.

A importância de verificar o impacto que uma crise causa em determinado setor é compreender como esse acontecimento pode impactar a sociedade, na renda da população, na desigualdade econômica e desenvolvimento de um país ou região. No caso da aviação, a redução ou exclusão de uma linha aérea restringe o contato de determinada região com as demais. Esse tipo de transporte tem como característica marcante a rapidez, tanto para passageiros quanto cargas, por isso, a partir da indisponibilidade desse recurso a região afetada 
brasileiro (Azul, 2020). Em 2006 a GOL inaugurou um Centro de Manutenção de aeronaves que fez parte do plano de redução de custos (Gol, 2020). Em 2018 adotou horário diferenciado para o check-in, para otimizar o tempo de embarque dos passageiros.

A situação de dificuldades financeiras se repete nos aeroportos, pois dos onze aeroportos concedidos, somente quatro registraram lucro no exercício de 2018, o que não é diferente no caso dos aeroportos administrados pela Infraero (Mattos \& Renzetti, 2020). A chegada da pandemia de Covid-19 não auxiliou muito na recuperação do setor aéreo, conforme abordagem do próximo tópico.

\section{Cenário econômico da aviação civil no Brasil durante a pandemia de Covid-19}

A pandemia de Covid-19 iniciou em dezembro 2019 na cidade de Wuhan na China, chegou ao Brasil entre os meses de fevereiro e março de 2020. O Covid-19 faz parte de uma grande família de vírus como MERS-CoV e SARS-CoV, e de acordo com o Ministério da Saúde (2020) esses vírus afetam animais, mas raramente são transmitidos para humanos.

Como o comportamento do novo vírus é de alto contágio se transformou rapidamente em pandemia fazendo com que a Organização Mundial da Saúde - OMS emitisse alertas para tentar reduzir a disseminação (Rodrigues, 2020). Os alertas, a letalidade da doença e a disseminação do vírus geraram ações políticas de saúde pública que indicaram o isolamento social, tanto no Brasil, quanto na maioria dos países pelo mundo. A ANAC (2020) divulgou em 28/03/2020 a "malha aérea esséncial" em que indicava a relação dos aeroportos que permaneceriam atendidos durante o mês de abril do mesmo ano. Foram mantidos os serviços aéreos das capitais estaduais.

Com o avanço da pandemia, fechamentos de fronteiras, redução do turismo e isolamento social a situação das Companhias aéreas ficou ainda mais complexa. A centralização aumentou os custos operacionais para algumas Companhias, mas a descentralização das operações para aeroportos regionais pode aumentar a probabilidade de contágio das redes (Rodrigues, 2020). O impacto ocorrerá nos custos fixos e na demanda em função da retração da renda mundial, o que é operacionalmente mais preocupante para as LLCs (Mattos \& Renzetti, 2020). Esse modelo de negócio depende da eficiência operacional e menor tempo nos aeroportos combinado a atuação em localidades menores, em que a demanda tende a diminuir.

Os fabricantes de aeronaves registrarão quedas produtivas para os próximos cinco anos, a demanda de passageiros deve voltar ao patamar anterior a pandemia em meados de 2022 para voos domésticos, e em junho 2024 para vos internacionais (Dyniewicz, 2020; Calixto, 2020).

Não é possível prever quando a recuperação deve ocorrer, pois o preço do dólar e 
combustível estão muito voláteis (Dyniewicz, 2020). Essas duas variáveis interferem nos custos operacionais das Companhias e variações constantes dificultam vislumbrar qualitativamente com precisão prazos de recuperação.

Com problemas de gestão e dificuldades financeiras anteriores a pandemia, as Companhias aéreas sofreram redução abrupta em abril de 2020, pois a redução dos voos chegou a 90\% no Brasil (Rodrigues, 2020). O Grupo Latam Airlines pediu recuperação judicial nos Estados Unidos, segundo a operação brasileira essa situação foi decorrente da pandemia, mas não deve atingir linhas aéreas no Brasil. A American Airlines informou prejuízo líquido US\$ 1,1 bilhão somente no primeiro trimestre. A Delta Air Lines informou perda de receitas com passagem de $94 \%$ no segundo trimestre, prejuízo líquido ajustado de US\$ 2,8 bilhões (Guimarães, 2020).

De acordo com dados apresentados pela ABEAR (2020), na Figura 1 estão indicadas as estatísticas sobrepostas de passageiros transportados mensalmente do período compreendido entre 2013 e 2020.

Figura1 - Passageiros transportados mensalmente de 2013 a 2020

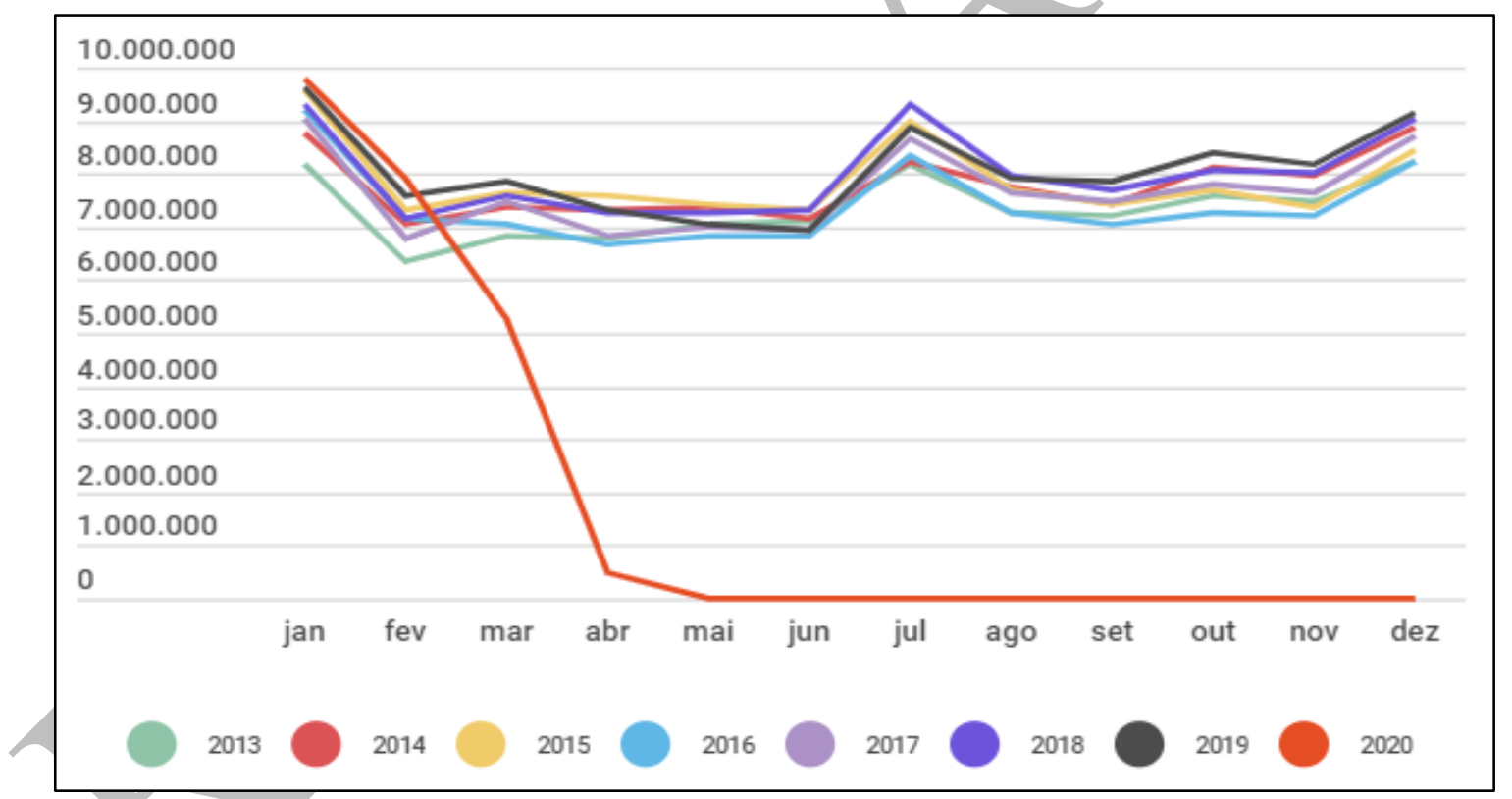

Fonte: ABEAR (2020).

As variáveis apresentadas na Figura 1 são consolidadas de acordo com a ABEAR (2020), define-se como a medida em RPK - Revenue Passenger - Kilometers ou Passageiros Quilômetros Pagos transportados. Pela Figura 1 é possível verificar a redução a partir de março de 2020 e a ausência de passageiros no restante do referido ano, pelo indicador. Na Figura 2, a estatística indicada na Figura 1 é demonstrada por Companhia aérea no mesmo período.

Figura 2 - Passageiros transportados por Companhia aérea de 2013 a 2020 em voos domésticos 


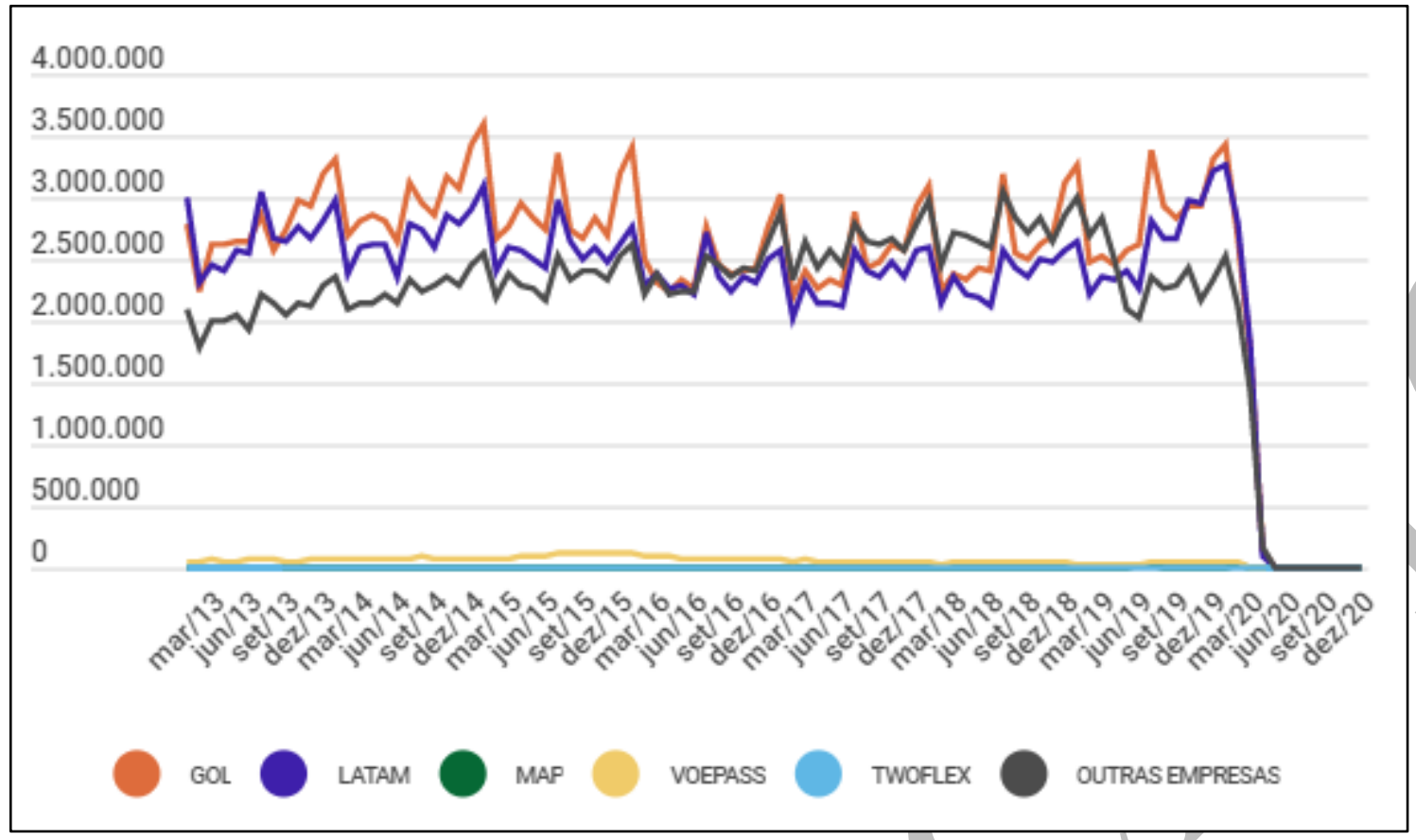

Fonte: ABEAR (2020).

A Figura 2 indica, de maneira contínua a quantidade de passageiros - quilômetros pago transportado das Companhias aéreas em voos domésticos. Destaca-se visualmente a participação de mercado das Companhias GOL e Latam, destaca-se que o crescimento da GOL acompanha a evolução do mercado aéreo. No entanto, o ano de 2019 foi muito positivo para o Grupo Latam. A Figura 3 apresenta o total de quilos de carga paga e correio transportados de 2013 a 2020 no mercado doméstico nacional.

Figura 3 - Totais mensais de carga paga e correio transportados doméstico (em Kg) de 2013 a 2020

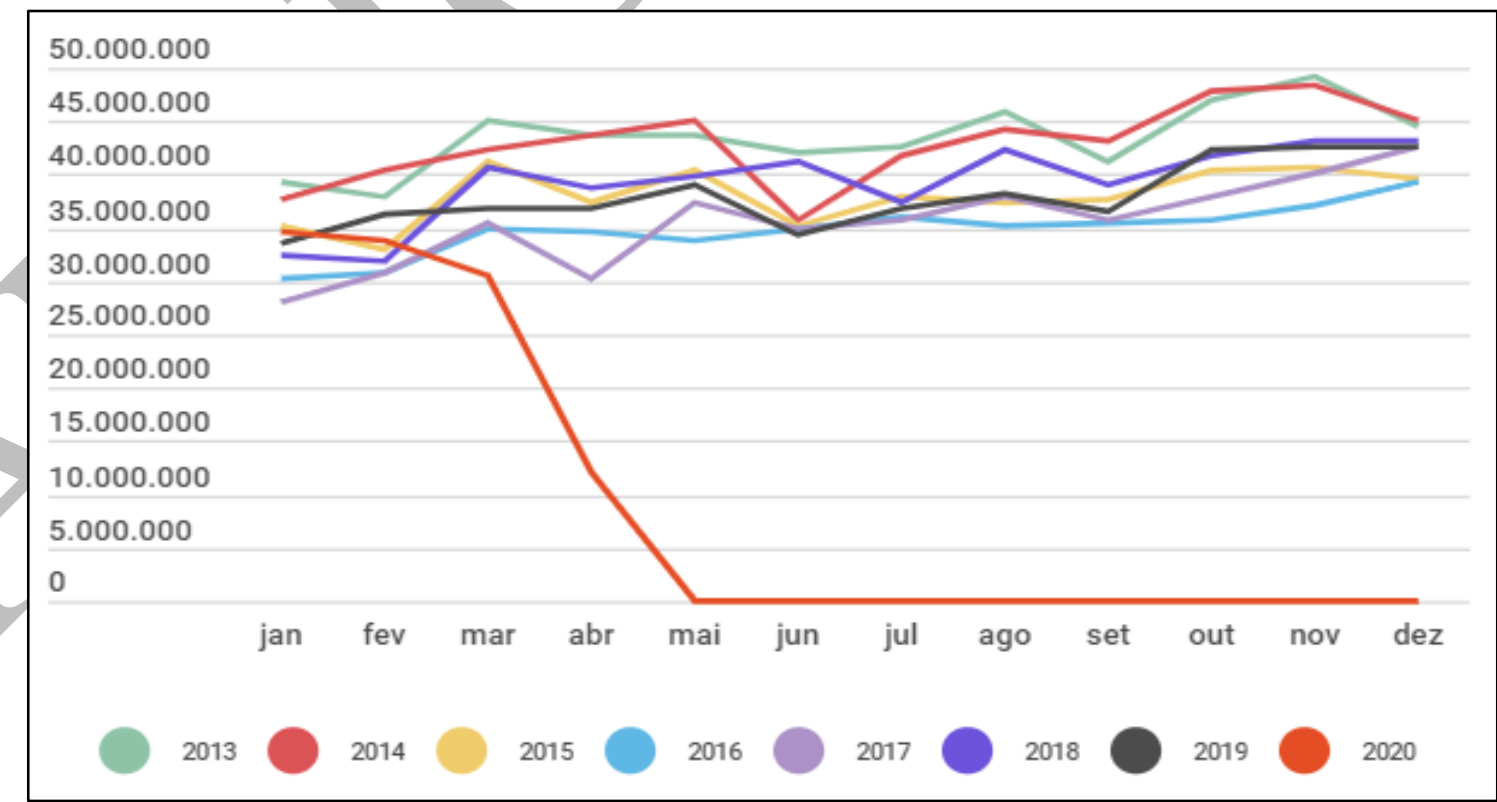

Fonte: ABEAR (2020) 


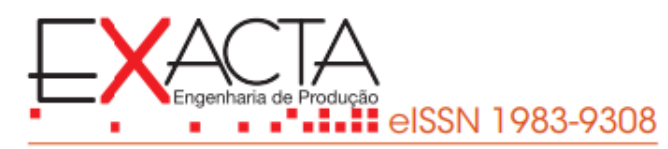

A Figura 3 demonstra que carga paga e correio foram transportadas via aérea por um período maior do que o transporte de passageiros. Contudo, a partir de maio de 2020, os dados da ABEAR indicam a parada desse tipo de transporte.

A crise resultante da pandemia de Covid-19 é a pior já enfrentada pelo setor, superando os ataques de 11 de setembro em 2001, a epidemia de SARS - síndrome respiratória aguda grave - em 2003 e a crise financeira do subprime de 2008 e 2009 que foi acompanhada pela epidemia de H1N1 (Mattos \& Renzetti, 2020). Com a retomada controlada das linhas aéreas no segundo semestre e o período de férias as Companhias começam a se recuperar da pior crise de liquidez já vista. Muito deverá ser feito até a retomada dos patamares que existiam em 2019, antes da pandemia.

\section{Metodologia}

As séries temporais selecionadas para este estudo são provenientes das fontes secundárias, o Ipeadata e a ABEAR. Foram utilizadas três series temporais, o número de passageiros embarcados em voos aéreos domésticos de 1969 a 2019, obtendo-se 51 observações coletadas no site do Ipeadata (www.ipeadata.com.br). A série de passageiros, medido em RPK - Revenue Passenger-Kilometers e a série de totais mensais de carga paga e correio transportados em Kg, ambas com 88 observações mensais de janeiro de 2013 a abril de 2020, coletadas no site da Associação Brasileira das Empresas Aéreas - ABEAR (https://www.ABEAR.com.br).

As séries temporais são observações que ocorre periodicamente ao longo do tempo (Morettin, \& Toloi, 2004) e, elas foram aplicadas a metodologia Box-Jenkinks realizando a modelagem autoregressive integrated muving average (ARIMA) com o auxílio do software $\mathrm{R}$ Studio.

A metodologia Box-Jenkins (1994) é utilizada para efetuar previsões em séries temporais que apresentem autocorrelações, por meio dos modelos ARIMA. A modelagem ARIMA é baseada em um ciclo iterativo que passa pelas fases de identificação do modelo; estimação dos parâmetros; diagnóstico e adequação do modelo. O modelo que apresentar as características de resíduo ruído branco e menores valores para as estatísticas de ajustes serão selecionados para se realizar previsões (Box, Jenkins \& Reinsel, 1994). O ciclo possui duas ideias fundamentais, a parcimônia e a iteração entre as fases. Parcimônia é o uso do menor número possível de parâmetros no modelo matemático e a iteração é a repetição da ação pela quantidade de vezes que for necessária (Morettin, \& Toloi, 2004). 
Entende-se por ruído branco um conjunto de variáveis aleatórias distribuídas de forma idêntica com média igual a zero, e variância constante e não autocorrelacionadas.

O filtro MA(q), médias móveis de ordem q, é dada por $\mathrm{y}_{\mathrm{t}}=\varepsilon_{\mathrm{t}}-\theta_{1} \varepsilon_{\mathrm{t}-1}-\ldots-\theta_{\mathrm{q}} \varepsilon_{\mathrm{t}-\mathrm{q}}$. $\mathrm{O} \theta$ são as constantes reais e et o ruído branco. A equação completa do modelo ARIMA(p,d,q) provêm da composição das partes $\operatorname{AR}(\mathrm{p})$ e $\mathrm{MA}(\mathrm{q})$, pela equação $\Delta^{\mathrm{d}} \mathrm{y}=\varphi_{1} \mathrm{y}_{\mathrm{t}-1}+\varphi_{2} \mathrm{y}_{\mathrm{t}-2}+\ldots+\varphi_{\mathrm{p}}$ $\mathrm{y}_{\mathrm{t}-\mathrm{p} .}+\varepsilon_{\mathrm{t}}-\theta_{1} \varepsilon_{\mathrm{t}-1}-\ldots-\theta_{\mathrm{q}} \varepsilon_{\mathrm{t}-\mathrm{q}}($ Morettin, 2008).

Os modelos ARIMA possuem variações de acordo coma as características de cada série, como o modelo SARIMA(p,d,q)(P,D,Q) $)_{s}$ que decorre da equação $\phi(L) \Phi(L) \Delta^{\mathrm{d}} \Delta^{\mathrm{D}} \mathrm{y}_{\mathrm{t}}=\theta(\mathrm{L}) \Theta(\mathrm{L})$ $\varepsilon_{t}$ (Ferreira, Barros, Mattos, Oliveira, \& Duca, 2018). Nesse modelo a parte sazonal é indicada pela ordem $\mathrm{P}$ autorregressivo sazonal, Q médias móveis sazonal e D a ordem de diferença sazonal (Vicini \& Souza, 2007).

Para a validação dos modelos ajustados, serão utilizados apenas parâmetros significativos $(\mathrm{p}<0,05)$, resíduos oriundos do modelo com características de ruído branco e critérios penalizadores Akaike (AIC - Akaike Information Criteria) (1974) e Bayes (BIC Bayesian Information Criteria) (Bai \& Perron, 2003) mínimos para um modelo aceitável. AIC e BIC seguem as equações $\mathrm{AIC}=\ln \sigma_{\mathrm{e}}^{2}+(2(\mathrm{p}+\mathrm{q})) / \mathrm{n}$ e $\mathrm{BIC}=\ln \sigma_{\mathrm{e}}{ }^{2}+((\mathrm{p}+\mathrm{q}) \ln (\mathrm{n}) / \mathrm{n}$; em que p e q são os parâmetros conhecidos, né o tamanho da amostra, ln é o logaritmo neperiano e $\sigma_{\mathrm{e}}^{2}$ a variância estimada dos erros.

Os valores de AIC e BIC são confrontados, quanto menor for o resultado do cálculo destes critérios mais adequado será o modelo para a projeção dos valores futuros. Os valores das previsões serão por meio do Mean Absolute Percentage Error - MAPE, MAPE = $\frac{\sum_{t=1}^{n}\left|\left(y_{t}-\hat{y}_{t}\right) / y_{t}\right|}{n}$ indica o percentual do módulo de erros que não é contaminado pela série temporal, ou seja, indica o erro percentual da previsão (Ferreira, Barros, Mattos, Oliveira, \& Duca, 2018).

A modelagem das variáveis será por meio do software Livre R, tomando como base os comandos de Hyndman \& Athanasopoulos (2018). As previsões geradas pela modelagem ARIMA por meio do software R, são acompanhadas dos seus respectivos intervalos de confiança, a um nível de confiança de $80 \%$ e $95 \%$.

Os valores estimados foram passados para planilha eletrônica para comparação com as observações realizadas e para a geração dos gráficos que estão dispostos no próximo capítulo. 
Dos modelos estudados o que apresentou menores valores nos critérios de seleção AIC e BIC foi o SARIMA $(0,1,1)(0,1,1)_{12}$, com AIC: 2288,95 e BIC: 2295,74. Os modelos que apresentaram os segundo e terceiro menores critérios de seleção foram o $\operatorname{SARIMA}(0,1,2)(0,1,1)$ com AIC:2288,79 e BIC:2297,84 e o SARIMA(1,1,1)(0,1,1) com AIC:2289, 16 e BIC:2298,21. A equação gerada pelo modelo $\operatorname{SARIMA}(0,1,1)(0,1,1)_{12}$ foi $\Delta \hat{y}_{t}=-0,6290 \cdot \varepsilon_{t-1}-0,8734 . y_{t-12}+$ $\varepsilon_{t}$, o MAPE indicou - $0,6 \%$ de erro, as previsões provenientes deste e o intervalo de confiança com $95 \%$ de confiança estão dispostas na Tabela 2.

Tabela 2 - Previsões para a série totais mensais de carga paga e correio transportados para 2020

\begin{tabular}{lccc}
\hline $\begin{array}{c}\text { Período } \\
\text { (ano 2020) }\end{array}$ & Previsão & $\begin{array}{c}\text { Limite inferior confiança } \\
\mathbf{9 5 \%}\end{array}$ & $\begin{array}{c}\text { Limite superior } \\
\text { confiança 95\% }\end{array}$ \\
\hline Janeiro & 32.554 .348 & 28.316 .026 & 36.792 .669 \\
Fevereiro & 33.218 .070 & 28.700 .056 & 37.736 .084 \\
Março & 38.275 .441 & 33.494 .068 & 43.056 .815 \\
Abril & 36.619 .340 & 31.588 .375 & 41.650 .306 \\
Maio & 38.750 .246 & 33.481 .499 & 44.018 .994 \\
Junho & 35.828 .827 & 30.332 .575 & 41.325 .078 \\
Julho & 37.102 .423 & 31.387 .717 & 42.817 .129 \\
Agosto & 38.937 .116 & 33.012 .005 & 44.862 .228 \\
Setembro & 37.187 .323 & 31.059 .025 & 43.315 .620 \\
Outubro & 40.653 .697 & 34.328 .737 & 46.978 .657 \\
Novembro & 41.842 .798 & 35.327 .109 & 48.358 .486 \\
Dezembro & 41.380 .917 & 34.679 .926 & 48.081 .908 \\
\hline Total & $\mathbf{4 5 2 . 3 5 0 . 5 4 6}$ & $\mathbf{3 8 5 . 7 0 7 . 1 1 8}$ & $\mathbf{5 1 8 . 9 9 3 . 9 7 4}$ \\
\hline
\end{tabular}

Fonte: Autores.

$\mathrm{Na}$ Tabela 2 estão indicadâs as previsões mensais para o ano de 2020 e os limites do intervalo de confiança com 95\% de confiança. Para o ano de 2020 o somatório da previsão para o ano de 2020 foi de 452.350 .546 quilos de carga paga e correios transportados. A Figura 6 foi elaborada para facilitar a compreensão do comportamento da série de carga paga e correio transportado, em quilos, entre janeiro de 2013 e abril de 2020 e a previsão efetuada pelo modelo para $\mathrm{o}$ ano de 2020.

Figura 6 - Série de carga paga e correio transportados mensal de 2013 a 2020 e previsões para 2020 


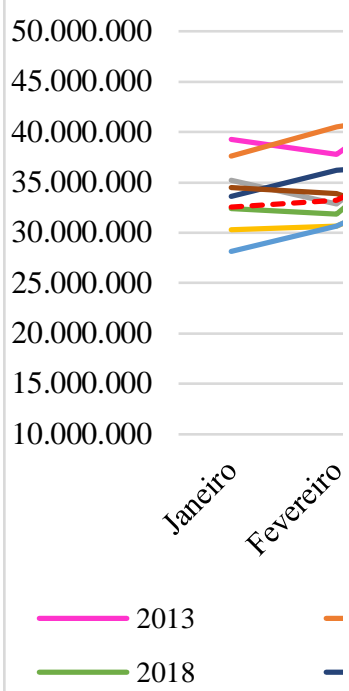

1

Fonte: Autores, adaptado de ABEAR (2020).

A série de carga paga e correio transportados, Figura 6, possui perfil distinto da série de passageiros, pois apresenta variações de um ano para outro. Não há a repetição de padrão durante os períodos. Os valores previstos para o ano de 2020 não coincidem com os ocorridos no primeiro quadrimestre, contudo nos meses de janeiro e fevereiro estes são mais próximos.

A ABEAR (2020) divulgou como resultado do primeiro quadrimestre de 2020 o total de 110.936.153 quilos de carga paga e correio transportados. Esse valor é 22,79\% inferior ao mesmo período do ano de 2019. A quantidade de carga paga e correio transportados por quadrimestre é em média $31,16 \%$ no primeiro quadrimestre, 33,31 no segundo e $35,53 \%$ no quarto, considerando o período de 2013 a 2019. Utilizando como valor de referência o resultado do primeiro quadrimestre de 2020, a estimativa de carga paga e correio transportados no ano é de 355.983.041 quilos, $21,97 \%$ inferior a 2019 e 21,30\% abaixo do previsto pelo modelo. Comparando com o limite inferior do intervalo de confiança 385.707 .118 a estimativa é $7,7 \%$ menor do que a carga estimada. O modelo previu 452.350.546 quilos, conforme Tabela 2, desse modo, sem o transporte de carga paga e correio transportados nos dois últimos quadrimestre do ano a redução chegou a 75,48\% para o ano de 2020.

Pelos valores previstos com o auxílio dos modelos de previsão de Box Jenkins e os resultados do primeiro quadrimestre a redução de passageiros transportados na aviação doméstica brasileira ficou compreendida entre $27,82 \%$ e $54,14 \%$ e a redução de carga paga e correio transportados em quilos entre $21,30 \%$ e 75,48\%. Essas reduções podem gerar consequências sérias para a saúde financeira e a manutenção das empresas aéreas no mercado nacional. 


\section{Considerações Finais}

A aviação civil no Brasil passou por várias transformações, algumas Companhias modificaram o modelo tradicional para o LLC com o intuito de aumentar as margens de lucro. Para que isso aconteça é necessário manter as aeronaves mais tempo em voo e menor tempo possível no solo. A situação econômica do setor estava prejudicada e em recuperação devido a crise de 2008 e com o período de pandemia e o isolamento social, será necessário tempo para a reverter o atual cenário.

Pelo estudo estima-se que a perda de passageiros transportados seja de, no mínimo, $27,82 \%$ e $21,30 \%$ para carga paga e correio transportado, a redução pode chegar a $55 \%$. No entanto, esses resultados são válidos caso o segundo e o terceiro quadrimestres de 2020 tenham performado de forma semelhante ao primeiro. Sendo assim, a brusca redução das receitas geradas pela diminuição da atividade das Companhias pode comprometer a saúde financeira e a manutenção do funcionamento destas no mercado.

A contribuição acadêmica do estudo decorre das análises geradas e da aplicação da metodologia Box-Jenkins, pois pelos resultados obtidos e as comparações com os valores observados geram informações que servem de embasamento para a tomada de decisões assertivas de gestores atuantes na aviação e de outras áreas produtivas. O intuito é mostrar que aplicação de métodos mais robustos de previsão são capazes de estimar perdas que, por vezes, as Companhias não vislumbram quando aplicam métodos mais simplificados, como comparação com o período anterior.

A principal limitação enfrentada pelo estudo foi a falta de publicação dos resultados das Companhias durante o ano de 2020. Como sugestão para outros estudos é a verificação do impacto do uso de ferramentas online para a aviação civil, visto que com a dificuldade para efetuar deslocamentos muitas empresas e pessoas substituíram suas atividades presenciais para o ambiente virtual. Cabem estudos que avaliem o quanto essa nova maneira de solucionar problemas e dar continuidade às atividades, de forma remota, podem interferir no transporte aéreo.

\section{Referências}

Agência Estado (2020). Coronavírus: Setor aéreo sofrerá impactos ao menos até 2023. Correio Brasiliense.

ANAC. Agência Nacional da Aviação Civil. Recuperado em 18 junho, 2020, de https://www.anac.gov.br/. 
Ferreira, P.C., Barros, A. C; Mattos, D. M; Oliveira, I. C. L.; Ferreira, P. G. C.; \& Duca, V. E. L. A. (2018). Análise de Séries Temporais em R: curso introdutório. Rio de Janeiro: Elsevier FGV IBRE.

Guimarães, L. (2020) Avianca e Latam mostram o tamanho da crise no setor aéreo. CNN Brasil Business. Recuperado em 04 janeiro, 2021, https://www.cnnbrasil.com.br/business/2020/07/15/avianca-latam-e-american-airlinesmostram-o-tamanho-da-crise-no-setor-aereo.

GOL. Nossa História. Recuperado em 22 de junho, 2020, de https://www.voegol.com.br/pt/informacoes/voos-gol?br=bannercarrossel1 \&of=compromisso-gol-voos.

Hyndman, R.J.; \& Athanasopoulos, G. (2018). Forecasting: principles and practice, 2nd ed. Melbourne: Australia.

Instituto de Pesquisa Econômica Aplicada (2020). Panorama e Perspectivas para o transporte aéreo no Brasil e no Mundo. [Texto para discussão, $\mathrm{N}^{\circ}$ 54].

Kwiatkowski, D., \& Phillips, P.C.B., Schmidt, P., Shin, Y. (1992). Testing the null hypothesis of stationarity against the alternative of a unit root. J. Econom. https://doi.org/10.1016/03044076(92)90104-y

Mattos, E. S.; Renzetti, B. P. (2020) Mayday: primeiras considerações sobre o impacto falimentar e concorrencial da COVID-19 sobre o setor aéreo e aeroportuário. Revista de Direito Público da Economia, 18(71), 25-46.

Mendonça, H. (2020). Em meio à pior crise de sua história, setor aéreo brasileiro vê esperança com férias de fim de ano. Jornal El País. Recuperado em 04 janeiro, 2021, de https://brasil.elpais.com/economia/2020-10-20/em-meio-a-pior-crise-de-sua-historia-setoraereo-brasileiro-ve-esperanca-com-ferias-de-fim-de-ano.html.

Melchior, C., Ricci, M. R., Andrade, F. B de., \& Zanini, R. R. (2019). Metodologia box-jenkins aplicada ao setor habitacional: um estudo de caso. Exacta, 17(4), 283-298. https://doi.org/10.5585/Exacta.v17n4.8525.

Ministério da Saúde. Sobre a doença: O que é Covid-19. Brasília, DF: Ministério da Saúde, 2020. Recuperado em 18 dezembro, 2020, de https://coronavirus.saude.gov.br/sobre-adoenca\#o-que-e-covid.

Morettin, P. A.; \& Toloi C. M. (2004). Métodos quantitativos: séries temporais. São Paulo.

Morettin, P. A. (2008). Enconometria financeira: um curso de séries temporais financeiras. São Paulo: Blucher.

Phillips, P.C.B., \& Perron, P. (1988). Testing for a unit root in time series regression. Biometrika 75, 335-346. https://doi.org/10.1093/biomet/75.2.335

Portal Brasil (2020). Aviação Avianca Brasil. Recuperado em 26 de junho, 2020, de https://www.portalbrasil.net/aviacao_avianca.htm. 
Reichert, B., \& Souza, A. M. (2020). Impacto da volatilidade no preço do cimento Portland. Exacta, 18(3), 475-488. https://doi.org/10.5585/ExactaEP.v18n3.10660.

Ribeiro, L. (2018). História da Aviação Civil e Origem do Setor de Transportes Aéreos no Brasil. Universidade do Sul de Santa Catarina, Tubarão, SC, Brasil.

Rodrigues, L. A. (2020). Transporte Aéreo de Passageiros e o Avanço da Covid-19 no Brasil. Revista Brasileira de Geografia Médica e da Saúde Hygeia, 1, 193 - 201. http://dx.doi.org/10.14393/Hygeia0054407

Silva, O.V.; \& Santos, R.C. (2009). Trajetória Histórica Da Aviação Mundial. Revista Científica Eletrônica de Turismo, 1(11), 1-5.

Silva, J. M. S.; Souza, M. A.; Machado, D. G. (2016) Desempenho de Empresas Brasileiras de Aviação Civil: uma análise das relações entre indicadores financeiros e não financeiros. Revista Espacios, 37, 23.

Vicini, L., \& Souza, A. M. (2007). Geração de subsídios para a tomada de decisão na cadeia produtiva da bovinocultura do Brasil. Gestão de Produção, Operações e Sistemas, 4, 49-64. 